\title{
Effect of Positive Devience Approach to Parenting in Malnutrition Children in Muke Village - East Nusa Tenggara - Indonesia
}

\author{
Florentianus Tat ${ }^{* 1}$, Elisabeth Herwanti ${ }^{1}$, Wanti $^{2}$, Kusmiyati ${ }^{2}$, Christine JK Ekawati ${ }^{2}$ \\ ${ }^{1}$ Department of Nursing Poltekkes Kemenkes Kupang \\ ${ }^{2}$ Department of Health Sanitation Poltekkes Kemenkes Kupang
}

Corresponding author: Email: Florentianus Tat; florentianustat@yahoo.co.id

Received 04 December 2019;

Accepted 16 December 2019;

Published 19 December 2019

\begin{abstract}
The percentage of malnutrition and stunting are still a major problem in east Nusa Tenggara Indonesia. Therefore we need a way to overcome these nutritional problems, among others, with the Positive Deviance Approach. This method is an act of community empowerment by transferring positive behaviour in mothers with malnutrition children. The research objective is Identify the effect of a positive deviance approach on mothers who have malnourished children. Subject and Method: this research is pre-experimental with one group pre-post test design. Data collection on 31 mothers who have malnutrition children. $\underline{\text { Result: }}$ after the intervention the mother's knowledge increases regarding feeding, child care and environmental health. After intervention maternal behavior increased regarding feeding, child care and environmental health. Statistical analysis shows that there is a significant influence between a positive deviance approach to experience with mothers' knowledge $(\mathrm{p}=0,03)$ and behavior $(\mathrm{p}=0,04)$ about feeding, caring for children and environmental health. Conclusion: The Positive Deviance approach gives an effect on increasing the knowledge and behavior of mothers in feeding, child care and environmental health. Recommendation: Use the Positive deviance method for changing people's behavior.
\end{abstract}

Keywords: Positive Deviance; malnutrition

\section{Introduction}

Nutrition problem in Indonesia is still a major problem in national development and needs to get more serious attention. Poor nutrition and poor nutrition are nutritional status based on body weight index according to age and this is still a problem in Indonesia, including East Nusa Tenggara Province. Based on regional health research 2018, the percentage of malnutrition in children aged 0-23 months in Indonesia is $3.8 \%$, while the percentage of malnutrition is 11.4. The province with the highest percentage of malnutrition and malnutrition among children aged 0-23 months in 2018 was East Nusa Tenggara Province which was $6.9 \%$ for malnutrition and $17.6 \%$ for malnutrition while West Java was the province with the lowest percentage which was $2.5 \%$ for malnutrition and 8.1 for malnutrition. Likewise in toddlers aged 0-59 months, East Nusa Tenggara Province also ranks first for the percentage of malnutrition and malnutrition (Kemenkes RI, 2019).

Nutrition problems in Indonesia are dominated by poor family socio-economic conditions (MOH RI, 2002). However, there are also those who are in a good economic condition but their toddlers suffer from malnutrition, which ultimately affects stunting. The problem of nutrition occurs not only because of poverty but also because of the behavior of mothers or people in the care of infants who are still lacking.

One way to overcome these nutritional problems is by using a positive deviation approach. This method is an act of community empowerment by transferring positive behavior in mothers of children under five who do not experience nutritional problems to mothers of children under five who experience nutrition problems. This study aims to identify parenting behaviors by toddlers who have nutritional problems with positive devience interventions.

\section{Research Methods}

The type of this research is Pre-Experimental with the design of this research is one group pre-test and post-test design by conducting a pre-test before being given intervention, after which a post-test is also conducted. The population of mothers who have children under five with nutritional problems in the Muke Village Region, Amabi Oefeto Timur District, Kupang NTT Regency. Samples are mothers of toddlers with nutritional problems. The stages of this research include: identification of the target group (PD ), Pre-test, Intervention 1: Pattern of feeding, Intervention 2: Child care, Intervention 3: STBM, post-test and finally post-test and processing and analysis of results 


\section{Results and Discussion}

1. Knowledge and Actions of Mothers of Toddlers with

Table 1: Knowledge of mothers with toddlers with nutritional problems before and after intervention Positive Deviance Approach The pattern of feeding, child care and STBM in Kupang Regency

\begin{tabular}{|l|c|c|c|c|c|c|}
\hline \multirow{2}{*}{ Knowledge } & Pretest & \multicolumn{2}{l|}{ Postest } & Less (\%) \\
\cline { 2 - 7 } & Well (\%) & Enough (\%) & Less (\%) & Well (\%) & Enough (\%) & Less (\%) \\
\hline Child Feeding & $27(8,7)$ & $1(0.3)$ & $3(1,0)$ & $31(100)$ & $0(0.0)$ & $0(0.0)$ \\
\hline Child Care & $28(9.0)$ & $3(1,0)$ & $0(0.0)$ & $31(100)$ & $0(0.0)$ & $0(0.0)$ \\
\hline STBM & $22(7,1)$ & $3(1,0)$ & $6(1,9)$ & $31(100)$ & $0(0.0)$ & $0(0.0)$ \\
\hline
\end{tabular}

Table 1 shows that there was a change in knowledge in mothers of children with nutritional problems after being given a Positive Deviance Approach intervention. Before there was PD intervention, it was found that sufficient and insufficient knowledge, but after being given PD intervention the knowledge of toddlers' mothers became all good (100\%).

Table 2: Actions of Mothers with Children under five with Nutritional Problems Before and After Intervention Positive Deviance Approach Pattern of feeding, Child Care and STBM in Kupang Regency

\begin{tabular}{|l|c|c|c|c|c|c|}
\hline \multirow{2}{*}{ Knowledge } & \multicolumn{2}{|l|}{ Pre-test } & \multicolumn{2}{l|}{ Post-test } & \multicolumn{1}{l|}{ Less (\%) } \\
\cline { 2 - 7 } & Well (\%) & Enough (\%) & Less (\%) & Well (\%) & Enough (\%) & $0(0.0)$ \\
\hline Child Feeding & $19(61.3)$ & $3(9.7)$ & $9(29.0)$ & $30(96.8)$ & $1(3,2)$ & $0(0.0)$ \\
\hline Child Care & $18(58.1)$ & $5(16.1)$ & $8(25.8$ & $30(96.8)$ & $1(3,2)$ & $(0.0)$ \\
\hline STBM & $20(64.5)$ & $5(16.1)$ & $6(19.4)$ & $31(100$ & $0(0.0)$ & 2 \\
\hline
\end{tabular}

Table 2 shows that at the time of the pre-test the actions of the community in feeding children, care and STBM were still included in the category of insufficient and insufficient, even in feeding children nearly $30 \%$ of mothers of children under five with nutritional problems. Whereas at the time of the post-test, which is after the second PD intervention, there seems to be a change in the actions of mothers of toddlers with nutritional problems.

\section{Positive Deviance Approach Mother With a Good Nutrition Toddler}

Positive Deviance Approach is carried out to see changes in knowledge and actions of mothers with toddlers with nutritional problems. Positive Deviance Approach is a state of positive deviation related to the health, growth and development of other children in the community environment that explains the factors that influence growth and good nutritional status of children who live in poor families and live in the environment poor (slum) where most other children suffer from growth and development disorders with conditions experiencing malnutrition. Positive Deviance Approach is based on the assumption that some solutions to overcome nutritional problems already exist in the community, only need to be observed to be able to know the forms of positive deviations that exist from the community's behavior. Efforts can be made by utilizing local wisdom based on the belief that each individual has special and unusual habits and behaviors that enable them to find better ways to prevent malnutrition than their neighbors who have the same economic conditions but do not have behaviors that include positive deviations.

The Positive Deviance Approach study studies why so many babies and toddlers in a poor community are only a small proportion who are malnourished. The family habits that define as the core of the Positive Deviance Approach program are divided into three or four main categories, namely feeding, caring, hygiene, and getting health care (CORE, 2003).

Sternin, J. (2017). PD is the tool that enables us to discover the unique practices / beliefs that enable the positive deviant members of the community to outperform or find better solutions to problems than their neighbors. (PD is a tool that allows us to find unique practices / beliefs that enable members community that deviates positively to outperform or find better solutions to problems than they do). PD provides an excellent tool for advocacy regardless of subject matter, as long as the ultimate goal relates to behavioral change. (PD is an excellent tool for advocating any problem, as long as the main goal is related to behavioral change).
The results showed that identified 10 mothers in Muke village who have toddlers with good nutrition. These mothers have the same socioeconomic status with other communities with basic livelihoods as farmers. The ten mothers were identified because they already have deviant behavior in providing nutritional care and care for their children to manage environmental fibers around the house so that they are always clean. Identifying the unique behavior of PD mothers, among others in preparing food for infants and toddlers. The food provided is always prepare food properly, wash food ingredients, provide varied food to the baby. Give food according to the age of the child for example porridge mixed with eggs, vegetables and meat that is crushed in the form of porridge to be given to infants / toddlers according to their age. Besides toddlers are required to take a break during the afternoon, mothers also always ensure that their children eat three times a day. Mothers also have healthy latrines and mothers and children and all family members must wash their hands before and after eating or after defecating and urinating. PD mothers have demonstrated successful practices in providing care to infants and toddlers.

In line with research Merita, M., \& Hesty, H. (2019). showed that the positive deviance of nutritional habits in feeding $(91.9 \%)$, parenting $(86.0 \%)$, toddler hygiene $(69.8 \%)$, utilization of health facilities $(89.5 \%)$ were classified as good. Baxter, at.all. (2016). The positive deviance approach focuses on those who demonstrate exceptional performance, despite facing the same constraints as others. 'Positive deviants' are identified and hypotheses about how they succeed are generated. These hypotheses are tested and then disseminated within the wider community. (The positive deviation approach focuses on those who show exceptional performance, despite facing the same obstacles as the others. 'Positive deviations' are identified and hypotheses about how they succeed)

PD ladies in Muke Village have shown good performance in providing care to infants and toddlers so that they do not experience malnutrition or malnutrition problems. PD mothers 
interact with mothers who have babies and toddlers with nutritional problems. This interaction will change the knowledge and attitudes of mothers in care for children.

Sternin, J. (2017). The use of PD provides two distinctive advantages. First, by discovering and sharing the actual successful practices and behaviors utilised by the PDs, can make those behaviors accessible to others. The second is the enlistment of the PDs themselves as advocates. 'Positive Deviance' —adeparture, difference, or deviation from the norm resulting in a positive outcome. (The use of PD provides two special advantages for those who work in advocacy. First, by finding and sharing actual successful practices and behaviors used by PDs, advocates can make these behaviors accessible to others. Second are registration of PDs themselves as defenders. 'Positive deviations' initial steps, differences, or deviations from the norm that produce positive things.). Baxter, at all. (2016) Positive deviation approach comes from the health of the international community. This has been used in a business approach and has been applied to health care.

\section{Identify Knowledge and Actions of Mothers of Toddlers with Nutritional Problems}

After being given an intervention in the form of Positive Deviance interaction in feeding patterns, child care and STBM, the data obtained from knowledge of mothers with nutritional problems of toddlers after given Positive Deviance Approach intervention namely before PD intervention was found sufficient and insufficient knowledge, but after being given PD intervention then mother's knowledge of toddlers is good all (100\%).

In line with the results of the study of Gizella, et al (2016). shows the maternal knowledge score increased from 80 to 92 ( $\mathrm{p}<0.001$ ) and the parenting score increased from 71 to 81 (p $<0.001$ ), and the nutritional status of children under five increased from before observing the median Z-Score BB / TB value of -2, 32 to -1.8 after observation $(\mathrm{p}<0.001)$. The conclusion of this research is the post nutrition program to improve mother's knowledge, parenting, and nutritional status of children under five.

Positive Deviance is a family-based approach that has a positive behavior that enable them to find ways better to prevent malnutrition. To reveal the experience of maintaining positive health in a family of positive deviance in an effort to improve the nutritional status of children under five (Luthfia, E., Yanti, Y., \& Warsiti, W. (2017).

Nutritional status is a sign of a person's appearance due to a balance between income and expenditure of nutrients derived from food consumed at any time based on the categories and indicators used (MOH, 2002). Indirectly the nutritional status of the community can be known based on an evaluation of quantitative and qualitative data on food consumption. Determination of nutritional status can be done in various ways namely biochemical, dietetic, clinical and anthropometric which is the most common and easy to use way to measure nutritional status in the field. Anthropometric index that can be used is weight per age, height per age, weight per height( $\mathrm{MOH}, 2005)$. Classification of nutritional status of children under five years old (Toddler) can be seen based on the threshold value or Z-Score called the standard deviation value. Anthropometric index of body weight per age $(\mathrm{Bb}$ / U) classification is divided into 4 categories namely over nutrition, good nutrition, poor nutrition and poor nutrition. For height value per age categorized in 2 parts, normal and short.

At the time of the community pretest in feeding children, care and STBM there were still included in the category of adequate and lacking, even in feeding children nearly $30 \%$ of mothers of children under five with nutritional problems. Whereas at the time of the post-test, which is after the second PD intervention, there seems to be a change in the actions of mothers of toddlers with nutritional problems.

Luthfia, et al. (2017) convey the results of a study that good health maintenance behavior can reduce the incidence of malnutrition. Need to increase family empowerment and share experiences among families Positive Deviance in an effort to improve the nutritional status of children under five.

\section{Effect of PD on Knowledge of Toddlers with Nutritional Problems}

Based on the results of PDA research, it affects the knowledge of mothers of children under five with nutritional problems with results $p=0.04$. Positive Deviance Approach is based on the assumption that some solutions to overcome nutritional problems already exist in the community, only need to be observed to be able to know the forms of positive deviations that exist from the community's behavior. Efforts can be made by utilizing local wisdom based on the belief that each individual has special and unusual habits and behaviors that enable them to find better ways to prevent malnutrition than their neighbors who have the same economic conditions but do not have behaviors that include positive deviations. The Positive Deviance Approach study studies why so many babies and toddlers in a poor community are only a small proportion who are malnourished. The family habits that define as the core of the Positive Deviance Approach program are divided into three or four main categories, namely feeding, caring, hygiene, and getting health care (CORE, 2003).

\section{The effect of PD on the behavior of toddlers with nutritional problems.}

Based on the results of PD research affect the behavior of mothers of children under five with nutritional problems with results $\mathrm{p}=$ 0.03 . case indicates that the PD is able to provide a positive influence on mothers of children with nutritional problems. This is because Mrs. PD comes from the same area and conditions as other communities.

This condition is the same as research presented by Lanita, et al (2015). It shows that toddlers who have good nutritional status from poor families have positive deviance behavior in the form of feeding habits, hygiene habits and habits using very good and correct health services. Whereas toddlers with poor / poor nutritional status from poor families have bad and bad habits that directly or indirectly affect the nutritional status of these toddlers.

Positive Deviance Approach is based on the assumption that some solutions to overcome nutritional problems already exist in the community, only need to be observed to be able to know the forms of positive deviations that exist from the community's behavior. Efforts can be made by utilizing local wisdom based on the belief that each individual has special and unusual habits and behaviors that enable them to find better ways to prevent malnutrition than their neighbors who have the same economic conditions but do not have behaviors that include positive deviations.

In line with research conducted by Saragih, B. (2017) Positive deviance (PD) mothers provide food menus based on the availability and preferences of toddlers. Feeding to persuade children to eat other than balanced nutrition is the strategy most often done by mothers as perpetrators of PD.

The Positive Deviance Approach study studies why so many babies and toddlers in a poor community are only a small proportion who are malnourished. The family habits that define as 
the core of the Positive Deviance Approach program are divided into three or four main categories, namely feeding, caring, hygiene, and getting health care (CORE, 2003).

Mothers who have toddlers with good nutritional status have positive deviance behavior in the form of daily habits in the form of feeding habits, hygiene and use of health services for their toddlers that are very good and correct compared to mothers who have toddlers with underweight nutritional status / bad even though they come from poor families (Lanita, et al (2015)

\section{Conclusion}

1. Positive Deviance Approach is carried out to see changes in knowledge and actions of mothers with toddlers with nutritional problems

2. Based on the results of PDA research, it affects the knowledge of mothers of children under five with nutritional problems with results $\mathrm{p}=0.04$

3. Based on the results of PDA research affect the behavior of mothers of children under five with nutritional problems with results $\mathrm{p}=0.03$

\section{Suggestion}

1. Community Health centers

In order to identify people who have positive behaviors in the health field

2. Village government

Empowering people who behave positively in the health sector to share information with the community as role models

3. Further research

In order to provide an opportunity to intervene with a longer time

\section{References}

[1] RI Ministry of Health. 2019. Indonesia Health Profile 2018. Jakarta. RI Ministry of Health,
[2] Green LW 1980. Health Education Planning, A Diagnostic Approach. The USA. The John Hopkins University, Myfeeld Publishing.

[3] MOH $\quad$ RI. $2002 . \quad$ Macro Nutrition Guidelines. Jakarta. Directorate of Community Nutrition.

[4] Sternin, J. (2017). Positive Deviance: A New Paradigm for Addressing Today's Problems Today 1. In Globalization and Corporate Citizenship: The Alternative Gaze (pp. 10-15). Routledge.

[5] Baxter, R., Taylor, N., Kellar, I., \& Lawton, R. (2016). What methods are used to apply positive deviance within healthcare organizations? A systematic review. BMJ Qual Saf, 25 (3), 190-201.

[6] Luthfia, E., Yanti, Y., \& Warsiti, W. (2017). Phenomenology Study: Positive Deviance Family Health Care Experiences in Efforts to Improve Toddler Nutritional Status in Puskesmas Ngumpakdalem Bojonegoro Regency. Journal of Research and Community Service Unsiq, 4 (2), 129-132.

[7] Merita, M., \& Hesty, H. (2019). Positive Nutritional Deviance In The Poor Family In New Village, Sarolangun Jambi. Journal of Applied Science And Technology, 13 (1), 55-66.

[8] Gizella, G., Hilmanto, D., Rachmadi, D., Husin, F., Gurnida, D., \& Herawati, DMD (2016). The Role of the Hearth Program through the Positive Deviance Approach to Increasing Knowledge, Mother Caring, and Its Impact on Increasing Toddler Nutrition Status in Tangerang City. Indonesian Journal of Education and Midwifery Care, 3 (1), 65-73.

[9] Saragih, B. (2017). Analysis of Positive Deviance Behavior in Feeding and Food Security of Poor Families. Magrobis Journal, 14 (1).

[10] Lanita, U., Febry, F., \& Mutahar, R. (2015). Description of Behavior Positive Deviance Nutritional Status of the Children Who Have 1-3 Years Old and Child Nutrition Maternal of Poor Families in the Village of Ulu Subdistrict Teaching Subdistrict, Ogan Ilir. Journal of Public Health Sciences, 3 (1), 24-34. 